US Army Corps

of Engineers $s_{\circledast}$

Engineer Research and

Development Center

Kinetics and Thermodynamics of Uranium (VI) Adsorption onto Humic Acid Derived from Leonardite

Fande Meng, Guodong Yuan, Steven L. Larson, John H. Ballard, July 2020

Jeremy R. White, Zikri Arslan, and Fengxiang X. Han 
The U.S. Army Engineer Research and Development Center (ERDC) solves the nation's toughest engineering and environmental challenges. ERDC develops innovative solutions in civil and military engineering, geospatial sciences, water resources, and environmental sciences for the Army, the Department of Defense, civilian agencies, and our nation's public good. Find out more at www.erdc.usace.army.mil.

To search for other technical reports published by ERDC, visit the ERDC online library at http://acwc.sdp.sirsi.net/client/default. 


\section{Kinetics and Thermodynamics of Uranium (VI) Adsorption onto Humic Acid Derived from Leonardite}

Steven L. Larson and John H. Ballard

Environmental Laboratory

U.S. Army Engineer Research and Development Center

3909 Halls Ferry Road

Vicksburg, MS 39180

Fande Meng, Jeremy R. White, Zikri Arslan, and Fengxiang X. Han

Department of Chemistry and Biochemistry

Jackson State University

Jackson, MS 39217

Guodong Yuan

School of Environmental and Chemical Engineering

Zhaoqing University

Zhaoqing, China 526061

Final report

Approved for public release; distribution is unlimited.

Prepared for U.S. Army Corps of Engineers

Washington, DC 20314

Under Project Number 458170, “Depleted Uranium (DU) Clearance from DoD Ranges" 


\section{Abstract}

Humic acid (HA) is well known as an inexpensive and effective adsorbent for heavy metal ions. However, the thermodynamics of uranium (U) adsorption onto HA is not fully understood. This study aimed to understand the kinetics and isotherms of $\mathrm{U}(\mathrm{VI})$ adsorption onto HA under different temperatures from acidic water. A leonardite-derived HA was characterized for its ash content, elemental compositions, and acidic functional groups, and used for the removal of $\mathrm{U}$ (VI) from acidic aqueous solutions via batch experiments at initial concentrations of $\mathrm{o}-100 \mathrm{mgL}^{-1}$ at 298,308 and $318 \mathrm{~K}$. ICP-MS was used to determine the U(VI) concentrations in solutions before and after reacting with the HA. The rate and capacity of HA adsorbing U(VI) increased with the temperature. Adsorption kinetic data was best fitted to the pseudo second-order model. This, together with FTIR spectra, indicated a chemisorption of U(VI) by HA. Equilibrium adsorption data was best fitted to the Langmuir and Temkin models. Thermodynamic parameters such as equilibrium constant $\left(\mathrm{K}_{0}\right)$, standard Gibbs free energy $\left(\Delta \mathrm{G}^{\circ}\right)$, standard enthalpy change $\left(\Delta \mathrm{H}^{\circ}\right)$, and standard entropy change $\left(\Delta \mathrm{S}^{\circ}\right)$, indicated that $\mathrm{U}(\mathrm{VI})$ adsorption onto HA was endothermic and spontaneous. The co-existence of cations $\left(\mathrm{Cu}^{2+}, \mathrm{Co}^{2+}, \mathrm{Cd}^{2+}\right.$ and $\left.\mathrm{Pb}^{2+}\right)$ and anions $\left(\mathrm{HPO}_{4}{ }^{2-}\right.$ and $\left.\mathrm{SO}_{4}{ }^{2-}\right)$ reduced $\mathrm{U}(\mathrm{VI})$ adsorption. The high propensity and capacity of leonardite-derived HA adsorbing U(VI) suggests that it has the potential for cost-effective removal of U(VI) from acidic contaminated waters.

DISCLAIMER: The contents of this report are not to be used for advertising, publication, or promotional purposes. Citation of trade names does not constitute an official endorsement or approval of the use of such commercial products. All product names and trademarks cited are the property of their respective owners. The findings of this report are not to be construed as an official Department of the Army position unless so designated by other authorized documents. 


\section{Preface}

This study was conducted for the U.S. Army Corps of Engineers under Project 458170, titled, "Depleted Uranium (DU) Clearance from DoD Ranges." The Grant Officer's Technical Representative was Mr. John H. Ballard, Office of the Technical Director for Installations and Operational Environments, ERDC-EL-EZT and the Technical Point of Contact was Dr. Steven L. Larson, Environmental Engineering Branch, ERDC-EL-EPE.

The work was performed by the Environmental Engineering Branch of the Environmental Processes Division, U.S. Army Engineer Research and Development Center, Environmental Laboratory (ERDC-EL). At the time of publication of this Miscellaneous Paper, Ms. Brooke Petery was Acting Branch Chief; Dr. Brandon Lafferty was Acting Division Chief; and Dr. Elizabeth Ferguson was the Technical Director for Installations and Operational Environments. The Acting Deputy Director of ERDC-EL was Dr. Justin Berman and the Acting Director was Dr. Jack Davis.

This report documents a collaborative study conducted under the sponsorship of the U.S. Army Futures Command with FY18 Congressional Program Increase Funds in PE 0603728A in the Fiscal Year (FY) 2018 Department of Defense Appropriations Act. Collaborative work was conducted by the U.S. Army Engineer Research and Development Center and Jackson State University via Cooperative Agreement W912HZ-16-2-0021.

The Commander of ERDC was COL Teresa A. Schlosser and the Director was Dr. David W. Pittman. 


\section{Kinetics and Thermodynamics of Uranium (VI) Adsorption onto Humic Acid Derived from Leonardite}

\section{Introduction}

Uranium (U) is widely but unevenly distributed in soils with an average concentration of $2.6 \mathrm{mg} \cdot \mathrm{kg}^{-1}$ [1]. Acid mining drainage is a major source of $U$ release into soil and water environments [2,3]. Naturally occurring U consists of three isotopes: U-238 (99.2739-99.2752\%), U-235 (0.7198-0.7202\%) and U-234 (0.0050-0.0059\%). In oxidizing environments $U$ is usually found in hexavalent form. U accumulation moves up the food chain, and eventually, to human organs and tissues, causing severe damage to kidneys, liver and in extreme cases, death [4]. The World Health Organization and US EPA have set the maximum concentration for U in drinking water at 15 and $30 \mu \mathrm{g} \cdot \mathrm{L}^{-1}$, respectively $[5,6]$. 
Adsorption, chemical precipitation, coagulation/flocculation, ultrafiltration and reverse osmosis are common processes used for removing $\mathrm{U}$ from wastewaters [7]. Adsorption of $\mathrm{U}(\mathrm{VI})$ onto insoluble adsorbents, such as clay minerals, activated carbon, biochar and natural biopolymers, has been investigated [8-12]. Humic acid (HA) is an inexpensive biopolymer with abundant functional groups (carboxylic and phenolic-hydroxyl), and it has been utilized to adsorb heavy metal ions [13].

$\mathrm{U}(\mathrm{VI})$ adsorption onto HA has been described with many models, including the pseudo second-order equation $[8,14]$. The thermodynamics of $\mathrm{U}(\mathrm{VI})$ adsorption onto HA, however, is not fully understood. This study aimed to understand the kinetics and isotherms of $\mathrm{U}(\mathrm{VI})$ adsorption onto HA under different temperatures from acidic water to reveal the equilibrium time, the mechanisms, and the capacities of $U$ adsorption onto HA.

\section{Materials and Methods}

\subsection{Materials and Reagents}

A leonardite was purchased from Leonardite Products, LLC, in Williston, ND, USA. All reagents used in this study were of analytical grade. Copper nitrate $\left(\mathrm{Cu}\left(\mathrm{NO}_{3}\right)_{2}\right)$, cadmium nitrate $\left(\mathrm{Cd}\left(\mathrm{NO}_{3}\right)_{2}\right)$, cobalt nitrate $\left(\mathrm{Co}\left(\mathrm{NO}_{3}\right)_{2}\right)$, hydrochloric acid $(\mathrm{HCl})$, lead nitrate $\left(\mathrm{Pb}\left(\mathrm{NO}_{3}\right)_{2}\right)$, nitric acid $\left(\mathrm{HNO}_{3}\right)$ and sodium hydroxide $(\mathrm{NaOH})$ were purchased from Thermo Fisher (Waltham, MA, USA). Uranyl nitrate (1\%) was purchased from Poly Scientific R\&D Corp (Bay Shore, NY, USA). U(VI) solutions were prepared for batch adsorption experiments by successively diluting the aqueous $1 \%$ uranyl nitrate with $1 \mathrm{mM}$ sodium nitrate $\left(\mathrm{NaNO}_{3}\right)$ as a background electrolyte [15]. $\mathrm{HNO}_{3}$ and $\mathrm{NaOH}$ were used for adjusting solution $\mathrm{pH}$.

\subsection{Preparation and Characterization of $H A$}

HA was extracted from the leonardite with traditional alkaline-acid protocol [8]. Briefly, $25 \mathrm{~g}$ leonardite was placed into a Teflon-container with $250 \mathrm{~mL} 0.1 \mathrm{M} \mathrm{NaOH}$ and sonicated for $30 \mathrm{~min}$. After standing overnight, the supernatant was collected. This process was repeated 2 more times for a total of 3 extractions. The collected supernatants were combined, and small aliquots of $6 \mathrm{M} \mathrm{HCl}$ was titrated in, while stirring, until the $\mathrm{pH}$ was reduced to 2 . The suspensions were then centrifuged at $3000 \mathrm{~g}$ for $15 \mathrm{~min}$. The precipitates (HA) were washed three times with distilled water and then freeze-dried for later use.

The physical and chemical properties of the leonardite and derived HA were analyzed as follows: Ash content was determined with ignition in a muffle furnace at $800^{\circ} \mathrm{C}$ for $4 \mathrm{~h}$ under atmospheric condition. Elemental compositions were determined with an elemental analyzer (Vario micro cube, Elementar, Germany) for dried samples at $80{ }^{\circ} \mathrm{C}$. Functional groups were identified with Fourier transform infrared spectroscopy (Spectrum Two, PerkinElmer, Waltham, MA, USA), and acidic functional groups were quantified with the titration method of the International Humic Substances Society [16].

\subsection{Adsorption Experiments and Data Processing}

All adsorption experiments were conducted in duplicates, including blanks and calibration controls. Briefly, $20 \mathrm{mg}$ of HA was weighed into $50 \mathrm{~mL}$ plastic centrifuge tubes (Corning, Corning, NY, USA) with $30 \mathrm{~mL} \mathrm{U}$ solution, and the $\mathrm{pH}$ of the suspension was adjusted to 3.0. The tubes were then shaken for $6 \mathrm{~h}$ to achieve equilibrium. Then, the tubes were centrifuged, and the supernatants were filtered through a $0.45 \mu \mathrm{m}$ membrane (Whatman, Little Chalfont, Buckinghamshire, UK) for analysis of $\mathrm{U}$ concentration with an ICP-MS (Varian Inc., Palo Alto, CA, USA). The $\mathrm{pH}$ at the beginning and end of adsorption experiment was measured by a pH meter (Oakton, Vernon Hills, IL, USA).

$\mathrm{U}$ adsorption on the HA was calculated from the difference in concentrations before and after the adsorption. MS-Excel and OriginPro 8.0 (OriginLab, Wellesley Hills, MA, USA) were used for data processing. 


\section{Models}

\subsection{Adsorption Kinetics Models}

Parameters obtained from four adsorption models were used to describe the kinetics of U(VI) adsorption onto HA: pseudo first-order model (Equation (1)) was used to describe the adsorption process in solid-liquid system at the initial phase, which corresponds to a diffusion-controlled process [17,18]; pseudo second-order model (Equation (2)) was used to describe whole adsorption process, involving chemisorption in solid-liquid system [18,19]; the Elovich equation (Equation (3)) was used to describe the chemisorption that occurred on heterogeneous solid surface [20,21]; and the intraparticle diffusion model (Equation (4)) was used to determine the intraparticle diffusion rate constant and the boundary resistance [22]. Detailed descriptions on the models and parameters are available in the literature [17-22].

$$
\begin{gathered}
q_{t}=q_{1}\left(1-e^{-k_{1} t}\right) \\
q_{t}=\frac{q_{2}^{2} k_{2} t}{1+q_{2} k_{2} t} \\
q_{t}=\frac{1}{\beta} \ln (\alpha \beta)+\frac{1}{\beta} \ln (t) \\
q_{t}=k_{i} t^{0.5}+C
\end{gathered}
$$

\subsection{Adsorption Isotherm Models}

Four adsorption isotherm models were used to describe $U$ distribution between solution and HA at the equilibrium state: the Freundlich model (Equation (5)) describes both monolayer and multilayer adsorption, which is based on heterogeneous adsorption in solid-liquid system [23,24]; the Langmuir model (Equation (6)) quantifies the adsorption capacity $[8,25,26]$; the Temkin model (Equation (7)) takes U-HA interaction into account and links adsorption energy to the adsorbent surface [27]; and the Dubinin-Radushkevich (D-R) model (Equation (8)) describes adsorption reaction at low concentration ranges on the homogeneous or heterogeneous surface [28].

$$
\begin{gathered}
q_{e}=k_{F} C_{e}^{1 / n} \\
q_{e}=\frac{q_{L} k_{L} C_{e}}{1+k_{L} C_{e}} \\
q_{e}=\frac{R T}{b} \ln k_{T}+\frac{R T}{b} \ln C_{e} \\
q_{e}=q_{D} e^{-k_{D} R T \ln \left(1+\frac{1}{C_{e}}\right)^{2}}
\end{gathered}
$$

\subsection{Thermodynamic Parameters}

The thermodynamic parameters are usually used to illustrate adsorption mechanisms and determine the reaction direction, which can be calculated from the thermodynamic equilibrium constant, $K_{0}$. The standard Gibbs free energy $\Delta G^{0}\left(\mathrm{~kJ} \cdot \mathrm{mol}^{-1}\right)$, standard enthalpy change $\Delta H^{0}\left(\mathrm{~kJ} \cdot \mathrm{mol}^{-1}\right)$, and standard entropy change $\Delta S^{0}\left(\mathrm{~J} \cdot \mathrm{mol}^{-1} \cdot \mathrm{K}^{-1}\right)$ were determined from the equations as follows:

$$
\begin{gathered}
\Delta G^{0}=-R T \ln K_{0} \\
\ln K_{0}=\frac{\Delta S^{0}}{R}-\frac{\Delta H^{0}}{R T}
\end{gathered}
$$


$K_{0}$ can be defined as,

$$
K_{0}=\frac{q_{e}}{C_{e}}
$$

where $R$ is the gas constant $\left(8.314 \mathrm{~J} \cdot \mathrm{mol}^{-1} \cdot \mathrm{K}^{-1}\right), T$ is the temperature in $\mathrm{K}, C_{e}$ is the equilibrium concentration $\left(\mathrm{mg} \cdot \mathrm{L}^{-1}\right)$, and $q_{e}$ is the amount of adsorption at equilibrium state $\left(\mathrm{mg}^{-1}\right)$.

\section{Results and Discussion}

\subsection{Properties of Adsorbents}

The properties of the leonardite and HA are shown in Table 1. HA had lower $\mathrm{pH}$ and ash content, but higher $\mathrm{C}$ and $\mathrm{O}$ contents than leonardite. Both $\mathrm{HA}$ and leonardite had abundant acidic functional groups (carboxyl and phenolic-hydroxyl), of which carboxyl groups are considered as the most important for adsorbing metal ions [13].

Table 1. The selected properties of leonardite and leonardite-derived humic acid (HA).

\begin{tabular}{cccccccccc}
\hline Adsorbents & $\mathrm{pH}\left(\mathrm{H}_{2} \mathrm{O}\right)$ & $\mathbf{A s h}(\%)$ & $\mathrm{C}(\%)$ & $\mathrm{H}(\%)$ & $\mathbf{N}(\%)$ & $\mathrm{S}(\%)$ & $\mathrm{O}(\%)$ & $-\mathrm{COOH}(\mathrm{mol} / \mathrm{kg})$ & Phenolic-OH $(\mathrm{mol} / \mathrm{kg})$ \\
\hline Leonardite & 3.99 & 17.77 & 49.21 & 3.48 & 1.01 & 0.47 & 28.06 & 3.04 & 1.10 \\
HA & 2.78 & 7.48 & 56.71 & 3.78 & 1.16 & 0.36 & 30.51 & 3.64 & 1.03 \\
\hline
\end{tabular}

The FTIR spectra of HA (Figure 1) confirmed the existence of oxygen-containing functional groups, as shown at wavenumbers of $3201 \mathrm{~cm}^{-1}\left(\mathrm{OH}\right.$ stretch of phenolic-OH), $1704 \mathrm{~cm}^{-1}(\mathrm{C}=\mathrm{C}$ stretch of $\mathrm{COOH}$ groups), $1601 \mathrm{~cm}^{-1}$ (asymmetric - $\mathrm{COO}^{-}$stretch), $1426 \mathrm{~cm}^{-1}$ (symmetric - $\mathrm{COO}^{-}$stretch), $1368 \mathrm{~cm}^{-1}$ (salts of $-\mathrm{COOH}), 1204 \mathrm{~cm}^{-1}(-\mathrm{C}-\mathrm{O}$ stretch and phenolic $\mathrm{C}-\mathrm{OH})$ and $1032 \mathrm{~cm}^{-1}\left(\mathrm{O}_{-} \mathrm{CH}_{3}\right.$ vibrations $)[29,30]$.

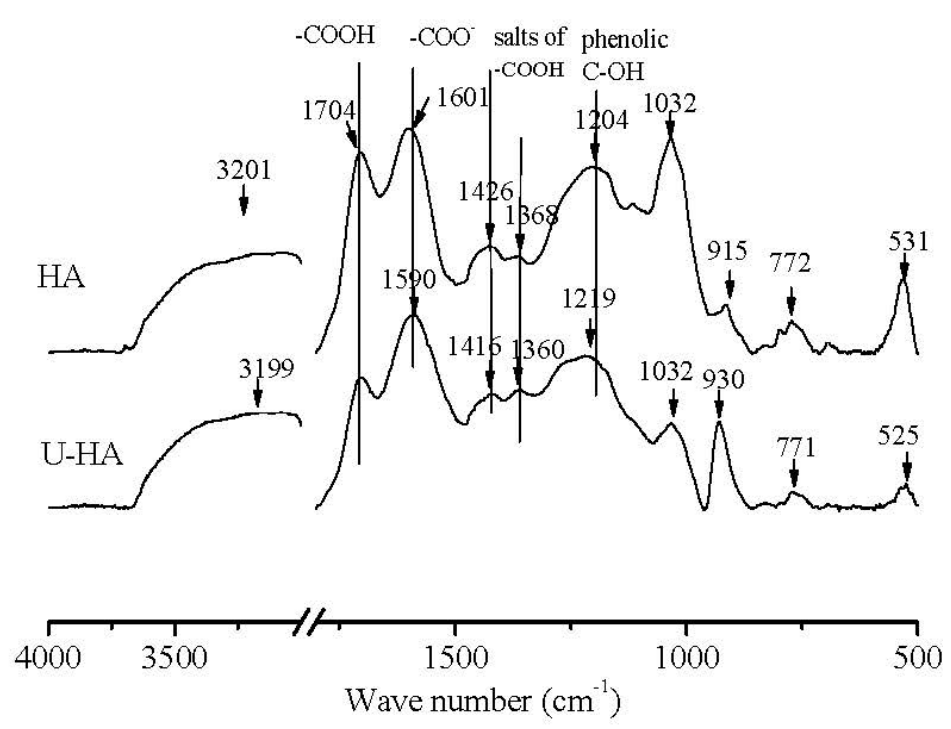

Figure 1. The FTIR spectra of humic acid (HA) before and after reaction with U(VI).

\subsection{Adsorption Kinetics}

Figures 2 and 3 show that $\mathrm{U}(\mathrm{VI})$ adsorption increased with rising temperature, indicating an endothermic process. This may be due to the increased binding sites of HA at a higher temperature [31]. Similar results were reported in the literature $[8,25,31]$. The time required for $\mathrm{U}(\mathrm{VI})$ adsorption process to reach equilibrium was $1.5 \mathrm{~h}$ at $298 \mathrm{~K}, 2 \mathrm{~h}$ at $308 \mathrm{~K}$ and $318 \mathrm{~K}$. 

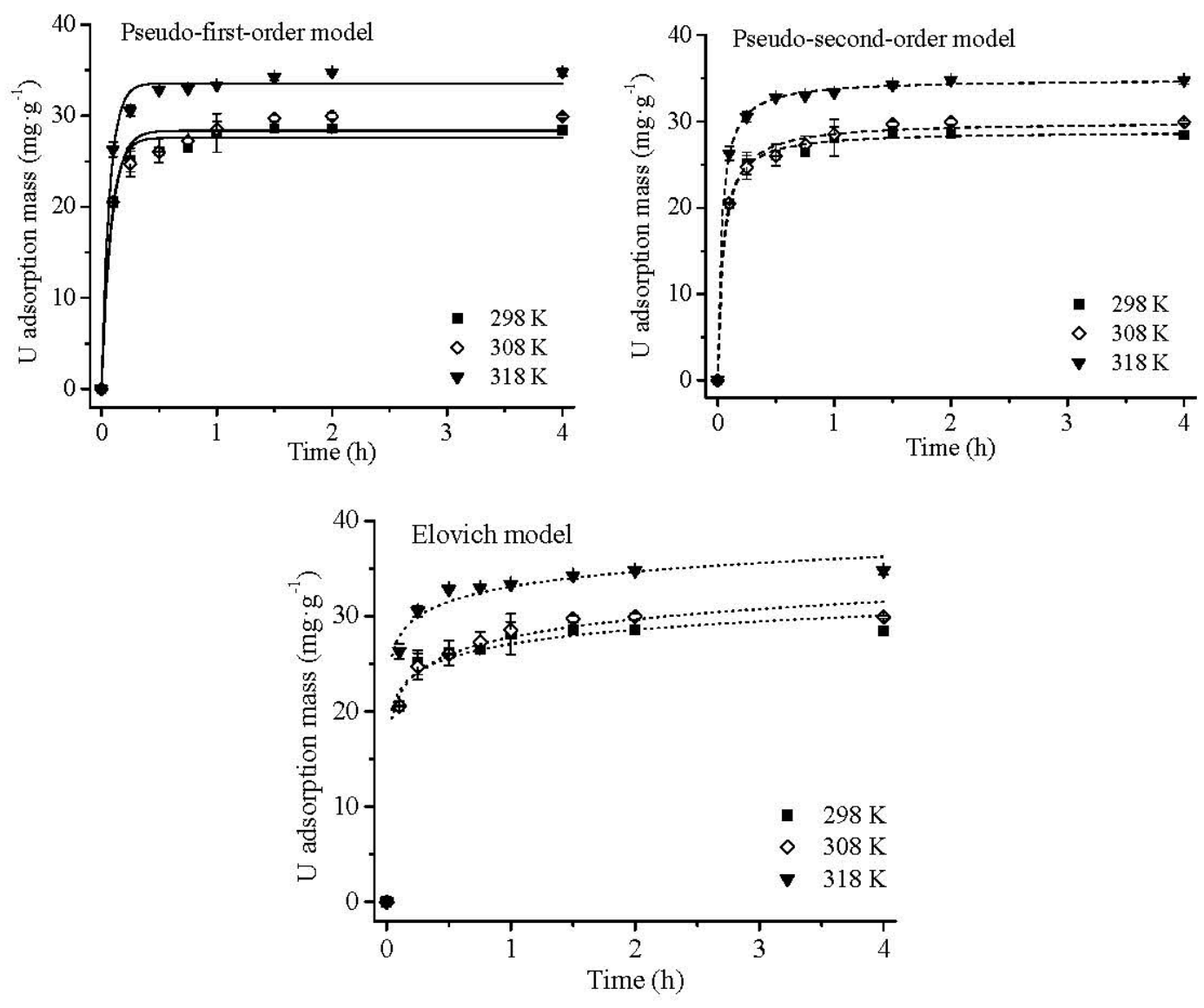

Figure 2. Kinetic models for $\mathrm{U}$ adsorption onto $\mathrm{HA}$ at different temperatures. Experimental conditions: adsorbent mass: $20 \mathrm{mg}$; solution volume: $30 \mathrm{~mL}$; U(VI) concentration: $60 \mathrm{mg} / \mathrm{L}$; contact time: $0.1,0.25$, $0.5,0.75,1,1.5,2$ and $4 \mathrm{~h}$; initial $\mathrm{pH}=3.0$; end $\mathrm{pH}: 2.70-2.90$.

Adsorption kinetics parameters are given in Table 2. The three models fit the adsorption process well $\left(R^{2}>0.95\right)$. The Elovich model had the highest $R^{2}$, indicating that $U(V I)$ adsorption onto HA may be chemisorption rather than intraparticle diffusion $[18,20]$. This was further evidenced by a low $R^{2}$ value from the intraparticle diffusion equation $(<0.70)$ in Table 3 , which suggests that the adsorption process was not controlled by intraparticle diffusion.

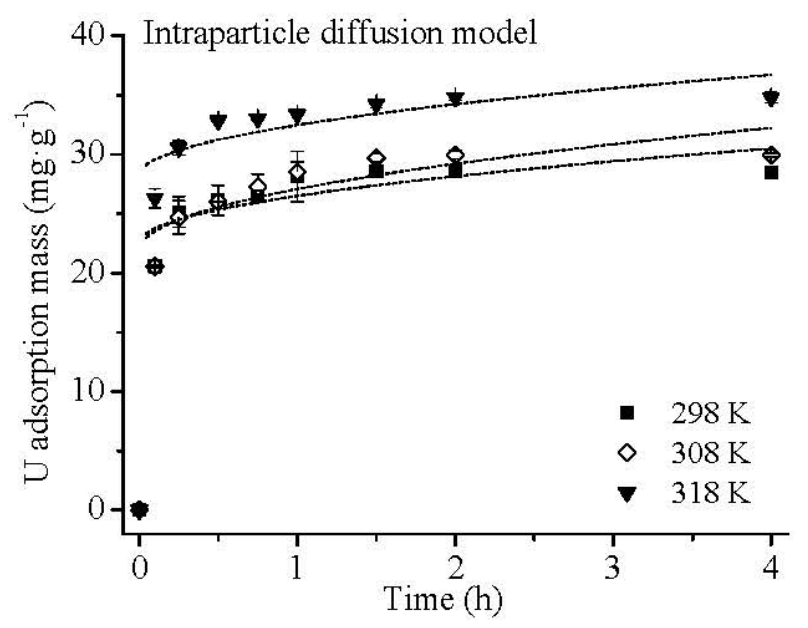

Figure 3. Intraparticle diffusion model for U(VI) adsorption onto $\mathrm{HA}$ at different temperatures. Experimental conditions: adsorbent mass: $20 \mathrm{mg}$; solution volume: $30 \mathrm{~mL}$; U(VI) concentration: $60 \mathrm{mg} / \mathrm{L}$; contact time: $0.1,0.25,0.5,0.75,1,1.5,2$ and $4 \mathrm{~h}$; initial $\mathrm{pH}=3.0$; end $\mathrm{pH}$ : $2.70-2.90$. 
Table 2. Parameters of kinetic models for U(VI) adsorption onto HA.

\begin{tabular}{|c|c|c|c|c|c|c|}
\hline \multirow{3}{*}{ Temperature $(K)$} & \multirow{3}{*}{$q_{e}\left(\mathbf{m g} \cdot \mathbf{g}^{-1}\right)$} & \multicolumn{5}{|c|}{ Isotherm Model } \\
\hline & & \multicolumn{2}{|c|}{ Pseudo First-Order } & \multicolumn{2}{|c|}{ Pseudo Second-Order } & \multirow{2}{*}{$\begin{array}{c}\text { Elovich } \\
\mathrm{R}^{2}\end{array}$} \\
\hline & & $q_{1}\left(\mathrm{mg} \cdot \mathrm{g}^{-1}\right)$ & $\mathrm{R}^{2}$ & $q_{2}\left(\mathrm{mg} \cdot \mathrm{g}^{-1}\right)$ & $\mathrm{R}^{2}$ & \\
\hline 298 & 28.60 & 27.58 & $0.986 * *$ & 28.86 & $0.997 * *$ & $0.986 * *$ \\
\hline 308 & 29.96 & 28.36 & 0.971 ** & 29.99 & 0.994 ** & 0.991 ** \\
\hline 318 & 34.79 & 33.56 & $0.989 * *$ & 34.89 & $0.999 * *$ & $0.992 * *$ \\
\hline
\end{tabular}

$q_{e}$ : the measured adsorption mass at equilibrium state; $q_{1}$ : the adsorption mass calculated by pseudo first-order at equilibrium state; $q_{2}$ : the adsorption mass calculated by pseudo second-order at equilibrium state; ${ }^{* *}$ Significant at 0.01 probability level.

Table 3. Intraparticle diffusion coefficients and intercept values for U(VI) adsorption on HA particles at different temperatures.

\begin{tabular}{cccc}
\hline Temperature $(K)$ & $\boldsymbol{k}_{\boldsymbol{i}}\left(\mathbf{m g} \cdot \mathbf{g}^{-1} \cdot \mathbf{h}^{0.5}\right)$ & $C\left(\mathbf{m g} \cdot \mathbf{g}^{-1}\right)$ & $\mathbf{R}^{2}$ \\
\hline 298 & 3.99 & 22.50 & $0.553^{* *}$ \\
308 & 5.17 & 21.89 & $0.684^{* *}$ \\
318 & 4.24 & 28.21 & $0.599^{* *}$ \\
\hline$k_{i:}$ the intraparticle diffusion rate constant; $C:$ a constant; ${ }^{* *}$ Significant at 0.01 probability level.
\end{tabular}

\subsection{Adsorption Isotherms}

As shown in Figure 4, adsorption capacity increased with $U$ concentrations. The parameters from fitting adsorption data into four isotherm models are given in Table 4.
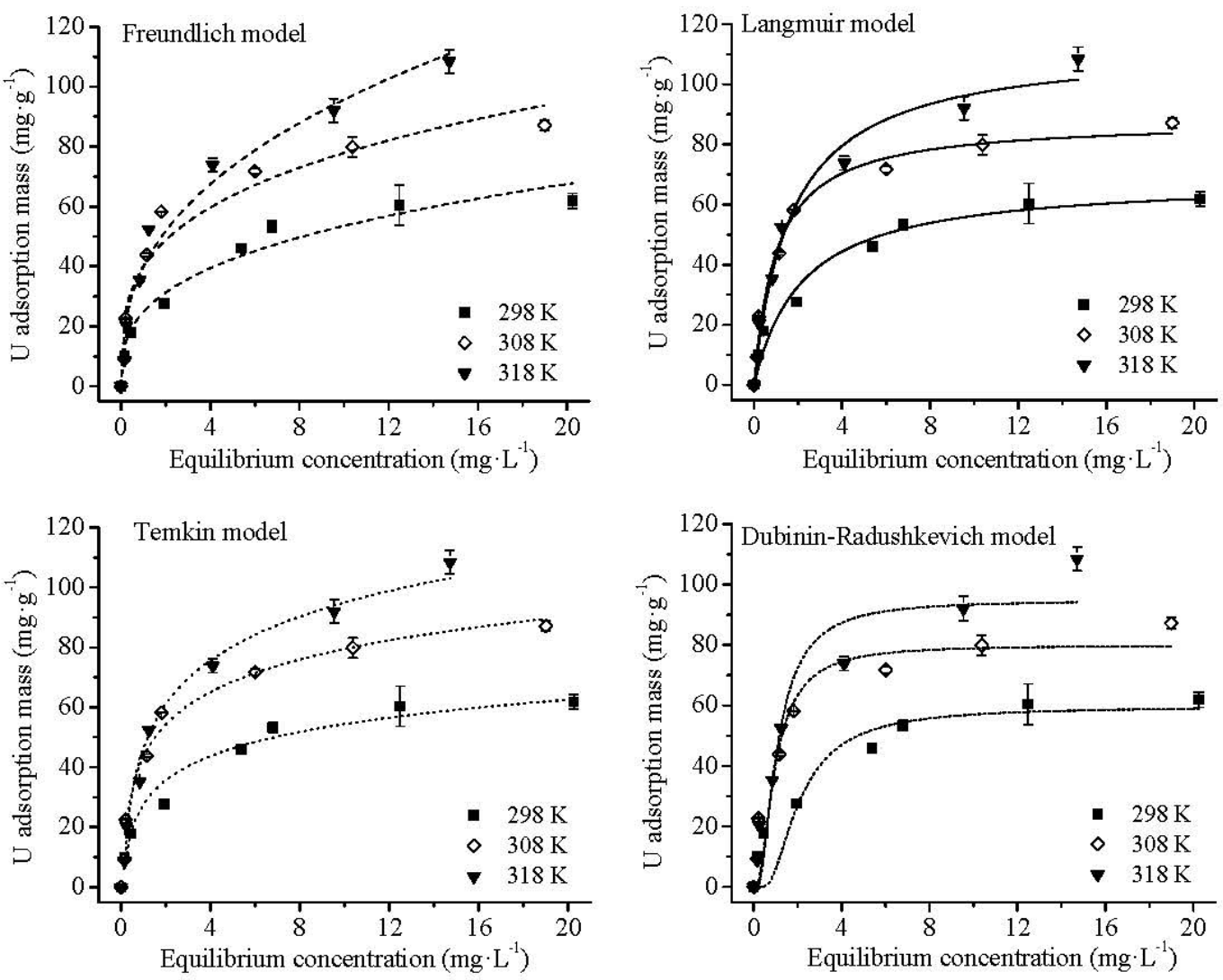

Figure 4. Isotherms of $\mathrm{U}(\mathrm{VI})$ adsorption onto $\mathrm{HA}$ at different temperatures. Experimental conditions: adsorbent mass: $20 \mathrm{mg}$; solution volume: $30 \mathrm{~mL}$; U(VI) concentration: 0, 5, 10, 20, 40,60, 80,100 mg/L; contact time: $6 \mathrm{~h}$; initial $\mathrm{pH}=3.0$; equilibrium $\mathrm{pH}: 2.60-2.90$. 
The $n$ values of Freundlich equation were higher than unity, indicating adsorption may be chemical rather than physical in nature with a high affinity of $\mathrm{HA}$ for $\mathrm{U}(\mathrm{VI})$, thus a high adsorption capacity [25,32]. Constant, $k_{F}$, was related to adsorption capacity. Its increase with temperature also confirmed that $\mathrm{U}(\mathrm{VI})$ adsorption on HA was endothermic. Adsorption data fit the Langmuir model well $\left(R^{2}>0.95\right)$. The maximum adsorption capacity $\left(q_{L}\right)$ at the concentration range of $0-100 \mathrm{mg} / \mathrm{L}$ increased with temperature. Even at acidic condition $(\mathrm{pH} 3), q_{L}$ of $68.6 \mathrm{mg}^{-1}$ was higher than the adsorption capacities of common adsorbents (kaolin, biochar, activated carbon, hematite, and bentonite) at near-neutral $\mathrm{pH}$ that would not be observed in acidic effluents (Table 5). The large adsorption capacity of $\mathrm{HA}$ for $\mathrm{U}$ is in agreement with its abundant carboxyl group [13]. The good fit of experimental data with Temkin equation $\left(R^{2}>0.97\right)$ implied that $U(V I)$ adsorption onto HA involved chemisorption [33] This was further supported by the results of pseudo second-order and Elovich equations. The $q_{D}$ values of $\mathrm{D}-\mathrm{R}$ model were not consistent with the $q_{L}$ calculated from the Langmuir isotherm as show in Figure 4 and Table 4 . Fitting of adsorption data into the D-R model produced the lowest $R^{2}$ in Table 4 , further suggesting $\mathrm{U}(\mathrm{VI})$ adsorption onto HA was not a physical process $[25,28,34,35]$.

Table 4. Parameters of adsorption isotherm models for U(VI) adsorption onto HA.

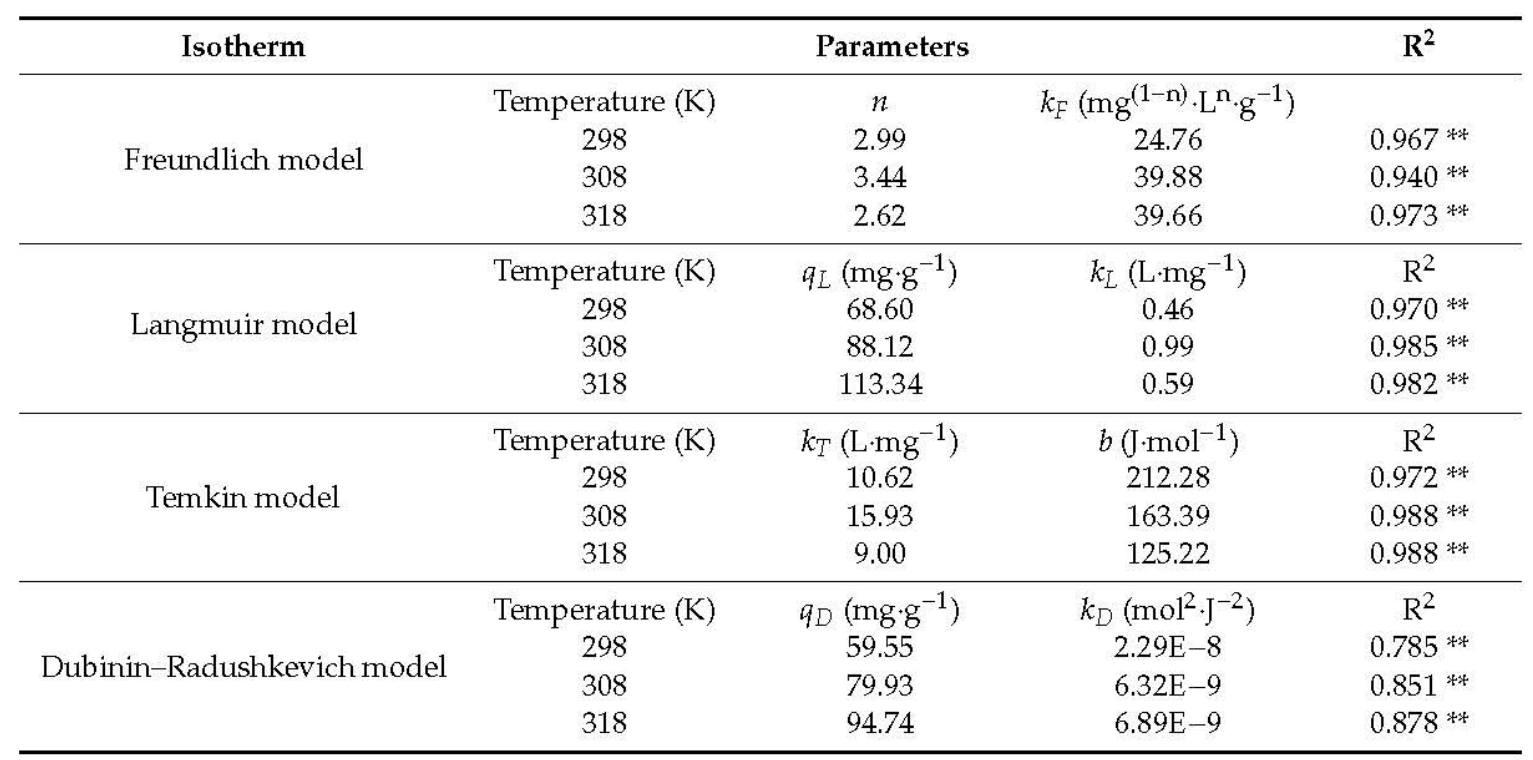

$n$ : a constant related to adsorption intensity; $k_{F}$ : the equilibrium adsorption constant related to adsorption capacity; $q_{L}$ and $q_{D}$ : the theoretical maximum capacity; $k_{L}$ : a constant related to the affinity of the binding sites; $k_{T}$ : Temkin isotherm equilibrium binding constant; $b$ : Temkin isotherm constant; $k_{D}$ : Dubinin-Radushkevich isotherm constant; ** Significant at 0.01 probability level.

Table 5. The comparison between this study and previous studies.

\begin{tabular}{ccccc}
\hline Materials & $C\left(\mathrm{mg} \mathrm{U}^{6+} / \mathrm{L}\right)$ & $\mathrm{pH}$ & $q_{m}(\mathrm{mg} / \mathrm{g})$ & References \\
\hline HA & $0-100$ & 3.0 & 68.60 & This study \\
Kaolin & $20-80$ & 5.0 & 4.52 & {$[10]$} \\
Biochar & $0-100$ & 6.0 & 62.70 & {$[11]$} \\
Activated Carbon & $100-200$ & 6.0 & 24.94 & {$[9]$} \\
Hematite & $0-100$ & - & 3.36 & {$[36]$} \\
Modified bentonite & $100-600$ & 6.0 & 29.6 & {$[37]$} \\
\hline
\end{tabular}

C: the $\mathrm{U}^{6+}$ concentration range; The $q_{m}$ was calculated from the Langmuir equation.

\subsection{Adsorption Thermodynamics}

The values of $\ln K_{0}$ at different temperatures were determined by linear plotting $\ln \left(\mathrm{q}_{\mathrm{e}} / \mathrm{C}_{\mathrm{e}}\right)$ versus $\mathrm{q}_{\mathrm{e}}$, assuming $\mathrm{q}_{\mathrm{e}}$ as zero as described in Figure $5 \mathrm{a}[8,14] . \Delta \mathrm{G}^{0}$ values were calculated from Equation (9) as displayed in Table $6 . \Delta H^{0}$ and $\Delta S^{0}$ were determined on the bases of Equation (10) by plotting $\ln K_{0}$ versus 
$1 / \mathrm{T}$, included in Figure $5 \mathrm{~b}$. The negative $\Delta G^{0}$ indicated that the adsorption reaction was spontaneous, and its extent of spontaneity increased with rising temperature. A positive $\Delta S^{0}=114.3 \mathrm{~J} \cdot \mathrm{mol}^{-1} \cdot \mathrm{K}^{-1}$ suggested that $\mathrm{U}(\mathrm{VI})$ adsorption onto $\mathrm{HA}$ was endothermic, which was supported by the higher adsorption capacity at higher temperature. A positive $\Delta H^{0}=23.13 \mathrm{~kJ} \cdot \mathrm{mol}^{-1}$ revealed that the HA had a high affinity for $\mathrm{U}(\mathrm{VI})$. Further, $\Delta H^{0}$ was a useful value to distinguish physisorption from chemisorption. In general, $\Delta H^{0}$ for physisorption is small, $2.1-20.9 \mathrm{~kJ} \cdot \mathrm{mol}^{-1}$, whereas $\Delta H^{0}$ for chemisorption is large, $20.9-418.4 \mathrm{~kJ} \cdot \mathrm{mol}^{-1}[38,39]$. The value of $\Delta H^{0}$ in the range of $20.9-418.4 \mathrm{~kJ} \cdot \mathrm{mol}^{-1}$ indicated that the adsorption of $\mathrm{U}(\mathrm{VI})$ onto HA involved chemisorption [39].
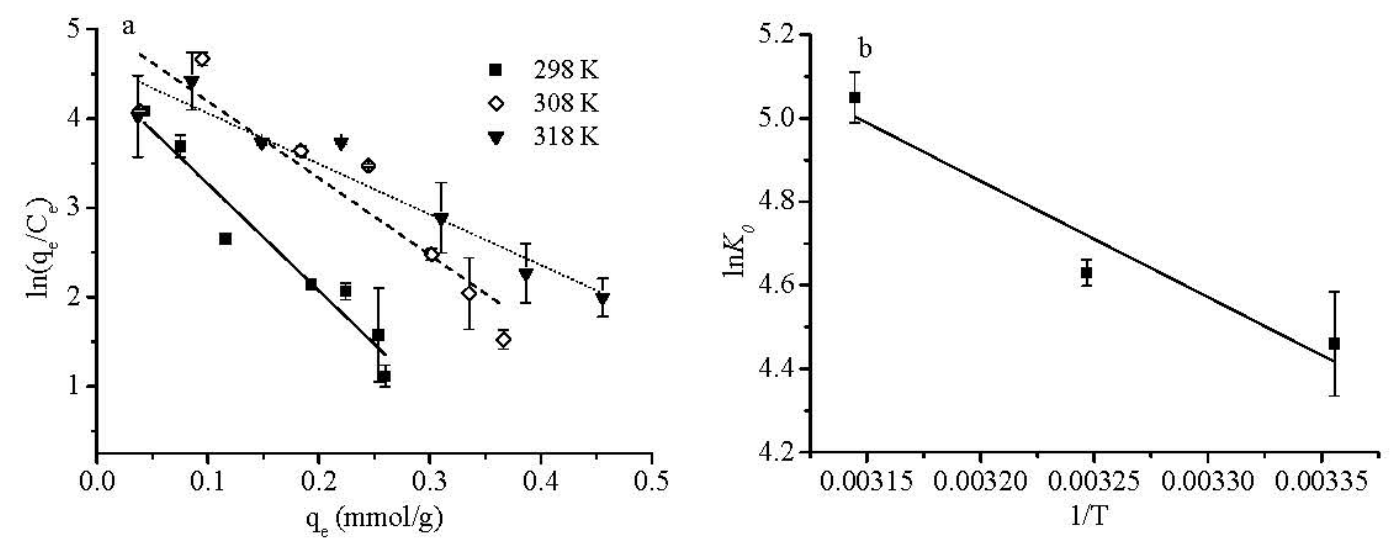

Figure 5. The calculation of thermodynamic parameters (a) $\ln K_{0}$, (b) $\Delta H^{0}$ and $\Delta S^{0}$.

Table 6. Thermodynamic parameters for U(VI) adsorption onto HA particles.

\begin{tabular}{ccc}
\hline Temperature $(\mathrm{K})$ & $\ln \boldsymbol{K}_{0}$ & $\Delta G^{0}\left(\mathrm{~kJ} \cdot \mathrm{mol}^{-1}\right)$ \\
\hline 298 & $4.46^{*}$ & -11.1 \\
308 & $4.63^{* *}$ & -12.2 \\
318 & $5.05^{* *}$ & -12.9 \\
\hline
\end{tabular}

* Significant at 0.05 probability level. ${ }^{*}$ Significant at 0.01 probability.

\subsection{Adsorption Mechanism}

FTIR is a useful tool to probe adsorption behavior of cations onto adsorbents $[8,23,40]$. The vibration frequency changes in characteristic peaks of $\mathrm{HA}$ before and after adsorption (Figure 1) include the shifts of the symmetric - $\mathrm{COO}^{-}$stretch frequency from 1601 to $1590 \mathrm{~cm}^{-1}$ (red shift), symmetric -COOstretch frequency from 1426 to $1416 \mathrm{~cm}^{-1}$ (red shift), salts of $-\mathrm{COOH}$ stretch frequency from 1368 to $1360 \mathrm{~cm}^{-1}$ (red shift), and phenolic $\mathrm{C}-\mathrm{OH}$ stretch frequency from 1204 to $1219 \mathrm{~cm}^{-1}$ (blue shift). Thus, U(VI) reacted with HA through functional groups [8,41]. The FTIR analysis further elaborated that $\mathrm{U}(\mathrm{VI})$ adsorption onto HA was via chemisorption. The adsorption process could be controlled by surface or intraparticle diffusion, and the intraparticle diffusion model is often used to make the judgment [22,42]. The parameters and $\mathrm{R}^{2}$ of data fitting into the intraparticle diffusion model are given in Table 3. The low $R^{2}(<0.7)$ suggested that the adsorption process was not controlled by intraparticle diffusion. In other words, surface diffusion was the dominant process for $\mathrm{U}(\mathrm{VI})$ adsorption onto $\mathrm{HA}$ via chemisorption, such as ion-exchange, complexation and chelation $[25,30]$.

\subsection{The Effects of Cations and Anions on U(VI) Adsorption}

Anions and cations are common in acidic $U$ contaminated water and in soil environment [43]. They may affect $\mathrm{U}(\mathrm{VI})$ adsorption onto HA. Figure 6 shows the effect of common cations and anions on $\mathrm{U}(\mathrm{VI})$ adsorption onto HA. The presence of $\mathrm{Cu}^{2+}, \mathrm{Co}^{2+}, \mathrm{Cd}^{2+}$ and $\mathrm{Pb}^{2+}$ cations reduced $\mathrm{U}(\mathrm{VI})$ adsorption capacity, which could be explained by the competitive adsorption of the cations for $\mathrm{U}(\mathrm{VI})[44,45]$. However, they are not good competitors for $\mathrm{U}(\mathrm{VI})$ and $\mathrm{Pb}^{2+}$ was the least competitive. 
The U(VI) adsorption decreased as co-existing cation concentrations increased, which is consistent with previous studies [46,47]. The presence of anions $\mathrm{HPO}_{4}{ }^{2-}$ and $\mathrm{SO}_{4}{ }^{2-}$ greatly reduced the adsorption capacity of $\mathrm{HA}$ for $\mathrm{U}(\mathrm{VI})$ as shown in Figure $6 \mathrm{~b}$. For $\mathrm{SO}_{4}{ }^{2-}$, the reduced adsorption may be caused by the competition between $\mathrm{SO}_{4}{ }^{2-}$ and $\mathrm{HA}_{\text {for }} \mathrm{UO}_{2}{ }^{2+}$, or the formation of negatively charged complexes with $\mathrm{UO}_{2}{ }^{2+}[43,48,49]$. At acidic condition, the $\mathrm{HPO}_{4}{ }^{2-}$ can react with $\mathrm{H}^{+}$to form $\mathrm{H}_{2} \mathrm{PO}_{4}{ }^{-}$and $\mathrm{H}_{3} \mathrm{PO}_{4}$ [50]. $\mathrm{HPO}_{4}{ }^{2-}$ had stronger effects than $\mathrm{SO}_{4}{ }^{2-}$. This may be caused by the formation of precipitation between $\mathrm{UO}_{2}{ }^{2+}$ and $\mathrm{HPO}_{4}{ }^{2-}, \mathrm{H}_{2} \mathrm{PO}_{4}{ }^{-}$and $\mathrm{H}_{3} \mathrm{PO}_{4}$, which could prevent $\mathrm{UO}_{2}{ }^{2+}$ being adsorbed onto HA surface [48,50-52].
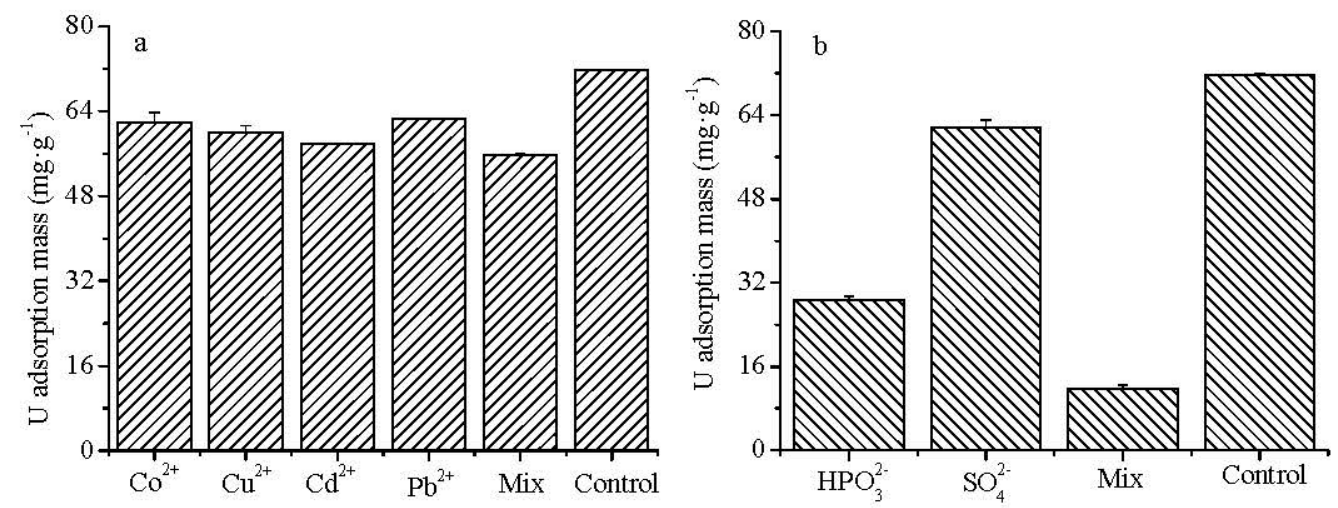

Figure 6. The effects of co-existing cations (a) or anions (b) on U(VI) adsorption onto HA. Experimental conditions: U(VI) concentration: $60 \mathrm{mg} / \mathrm{L}$; single cation concentration: $10 \mathrm{mg} / \mathrm{L}$; mix cation concentration: $40 \mathrm{mg} / \mathrm{L}$; single anion concentration: $50 \mathrm{mg} / \mathrm{L}$; mix anion concentration: $100 \mathrm{mg} / \mathrm{L}$; contact time: $6 \mathrm{~h}$; initial $\mathrm{pH}=3.0$; equilibrium $\mathrm{pH}=2.70-2.90$.

\section{Conclusions}

HA derived from leonardite was an effective adsorbent for removing uranium from aqueous acid solutions. The adsorption increased as temperature increased. Data fitting into kinetic models and large $\Delta H^{0}$ suggested that the adsorption involved chemisorption. The thermodynamic parameters indicated that the adsorption process was endothermic and spontaneous. Co-existing cations and anions had negative effects on U(VI) adsorption onto HA. Because of its wide availability and low-cost HA has a potential for use in the treatment of acidic mining effluents.

\section{References}

1. Rankin, D.W. CRC Handbook of Chemistry and Physics, 88th ed.; Taylor \& Francis Group: Boca Raton, FL, USA, 2008; pp. 14-17.

2. Campos, M.B.; de Azevedo, H.; Nascimento, M.R.L.; Roque, C.V.; Rodgher, S. Environmental assessment of water from a uranium mine (Caldas, Minas Gerais State, Brazil) in a decommissioning operation. Environ. Earth Sci. 2011, 62, 857-863. [CrossRef] 
3. Mudd, G.M.; Patterson, J. Continuing pollution from the Rum Jungle U-Cu project: A critical evaluation of environmental monitoring and rehabilitation. Environ. Pollut. 2010, 158, 1252-1260. [CrossRef] [PubMed]

4. Xie, S.; Yang, J.; Chen, C.; Zhang, X.; Wang, Q.; Zhang, C. Study on biosorption kinetics and thermodynamics of uranium by Citrobacter freudii. J. Environ. Radioactiv. 2008, 99, 126-133. [CrossRef] [PubMed]

5. U.S. Environmental Protection Agency. Drinking Water Standards and Health Advisories; EPA 822-S-12e1001; Office of Water; U.S. Environmental Protection Agency: Washington, DC, USA, 2012.

6. World Health Organization. Guidelines for Drinking-Water Quality, 3rd ed.; World Health Organization: Geneva, Switzerland, 2008.

7. Bhalara, P.D.; Punetha, D.; Balasubramanian, K. A review of potential remediation techniques for uranium(VI) ion retrieval from contaminated aqueous environment. J. Environ. Chem. Eng. 2014, 2, 1621-1634. [CrossRef]

8. Meng, F.D.; Yuan, G.D.; Larson, S.L.; Ballard, J.H.; Waggoner, C.A.; Arslan, Z.; Han, F.X. Removing uranium (VI) from aqueous solution with insoluble humic acid derived from leonardite. J. Environ. Radioactiv. 2017, 180, 1-8. [CrossRef] [PubMed]

9. D'Souza, S.F.; Sar, P.; Kazy, S.K.; Kubal, B.S. Uranium sorption by Pseudomonas biomass immobilized in radiation polymerized polyacrylamide bio-beads. J. Environ. Sci. Heal. A 2006, 41, 487-500. [CrossRef] [PubMed]

10. Haddad, D.; Mellah, A.; Nibou, D.; Khemaissia, S. Promising enhancement in the removal of uranium ions by surface-modified activated carbons: Kinetic and equilibrium studies. J. Environ. Chem. Eng. 2018, 144, 04018027. [CrossRef]

11. Wang, G.; Wang, X.; Chai, X.; Liu, J.; Deng, N. Adsorption of uranium (VI) from aqueous solution on calcined and acid-activated kaolin. Appl. Clay Sci. 2010, 47, 448-451. [CrossRef]

12. Zhang, Z.; Cao, X.; Liang, P.; Liu, Y. Adsorption of uranium from aqueous solution using biochar produced by hydrothermal carbonization. J. Radioanal. Nucl. Ch. 2013, 295, 1201-1208. [CrossRef]

13. Soler-Rovira, P.; Madejón, E.; Madejón, P.; Plaza, C. In situ remediation of metal contaminated soils with organic amendments: Role of humic acids in copper bioavailability. Chemosphere 2010, 79, 844-849. [CrossRef] [PubMed]

14. Khalili, F.; Al-Banna, C. Adsorption of uranium (VI) and thorium (IV) by insolubilized humic acid from Ajloun soil-Jordan. J. Environ. Radioactiv. 2015, 146, 16-26. [CrossRef]

15. Harter, R.D.; Naidu, R. An assessment of environmental and solution parameter impact on trace-metal sorption by soils. Soil Sci. Soc. Am. J. 2001, 65, 597-612. [CrossRef]

16. International Humic Substances Society. Acidic Functional Groups of IHSS Samples. 2018. Available online: http://humic-substances.org/acidic-functional-groups-of-ihss-samples/\#products (accessed on 27 April 2019).

17. Ho, Y.S. Citation review of Lagergren kinetic rate equation on adsorption reactions. Scientometrics 2004, 59, 171-177.

18. Simonin, J.P. On the comparison of pseudo-first order and pseudo-second order rate laws in the modeling of adsorption kinetics. Chem. Eng. J. 2016, 300, 254-263. [CrossRef]

19. Ho, Y.S.; McKay, G. Pseudo-second-order model for sorption processes. Process. Biochem. 1999, 34, 451-465. [CrossRef]

20. Inyang, H.I.; Onwawoma, A.; Bae, S. The Elovich equation as a predictor of lead and cadmium sorption rates on contaminant barrier minerals. Soil Till. Res. 2016, 155, 124-132. [CrossRef]

21. Juang, R.S.; Chen, M.K. Application of the Elovich equation to the kinetics of metal sorption with solvent-impregnated resins. Ind. Eng. Chem. Res. 1997, 36, 813-820. [CrossRef]

22. Wu, F.C.; Tseng, R.L.; Juang, R.S. Initial behavior of intraparticle diffusion model used in the description of adsorption kinetics. Chem. Eng. J. 2009, 153, 1-8. [CrossRef]

23. Meng, F.D.; Yuan, G.D.; Wei, J.; Bi, D.X.; Wang, H.L. Leonardite-derived humic substances are great adsorbents for cadmium. Environ. Sci. Pollut. R. 2017, 24, 23006-23014. [CrossRef] [PubMed]

24. Yang, C. Statistical mechanical study on the Freundlich isotherm equation. J. Colloid Interf. Sci. 1998, 208, 379-387. [CrossRef]

25. Boparai, H.K.; Joseph, M.; O'Carroll, D.M. Kinetics and thermodynamics of cadmium ion removal by adsorption onto nano zerovalent iron particles. J. Hazard. Mater. 2011, 186, 458-465. [CrossRef] [PubMed]

26. Sadeek, S.A.; Negm, N.A.; Hefni, H.H.H.; Wahab, M.M.A. Metal adsorption by agricultural biosorbents: Adsorption isotherm, kinetic and biosorbents chemical structures. Int. J. Biol. Macromol. 2015, 81, 400-409. [CrossRef] [PubMed] 
27. Aharoni, C.; Ungarish, M. Kinetics of activated chemisorption. Part 2-Theoretical models. J. Chem. Soc. Faraday Trans. 1 1977, 73, 456-464. [CrossRef]

28. Celebi, O.; Kilikli, A.; Erten, H.N. Sorption of radioactive cesium and barium ions onto solid humic acid. J. Hazard. Mater. 2009, 168, 695-703. [CrossRef]

29. Stevenson, F.J. Humus Chemistry: Genesis, Composition, Reactions, 2nd ed.; Wiley: New York, NY, USA, 1994.

30. Tan, K.H. Humic Matter in Soil and the Environment: Principles and Controversies, 2nd ed.; CRC Press: Boca Raton, FL, USA, 2014.

31. Mahmoud, M.A. Kinetics and thermodynamics of U (VI) ions from aqueous solution using oxide nanopowder. Process. Saf. Environ. 2016, 102, 44-53. [CrossRef]

32. Jiang, J.Q.; Zeng, Z. Comparison of modified montmorillonite adsorbents: Part II: The effects of the type of raw clays and modification conditions on the adsorption performance. Chemosphere 2003, 53, 53-62. [CrossRef]

33. Biswas, K.; Saha, S.K.; Ghosh, U.C. Adsorption of fluoride from aqueous solution by a synthetic iron (III)-aluminum (III) mixed oxide. Ind. Eng. Chem. Res. 2007, 46, 5346-5356. [CrossRef]

34. Foo, K.Y.; Hameed, B.H. Insights into the modeling of adsorption isotherm systems. Chem. Eng. J. 2010, 156, 2-10. [CrossRef]

35. Hutson, N.D.; Yang, R.T. Theoretical basis for the Dubinin-Radushkevitch (DR) adsorption isotherm equation. Adsorption 1997, 3, 189-195. [CrossRef]

36. Xie, S.; Zhang, C.; Zhou, X.; Yang, J.; Zhang, X.; Wang, J. Removal of uranium (VI) from aqueous solution by adsorption of hematite. J. Environ. Radioactiv. 2009, 100, 162-166.

37. Zareh, M.M.; Aldaher, A.; Hussein, A.E.M.; Mahfouz, M.G.; Soliman, M. Uranium adsorption from a liquid waste using thermally and chemically modified bentonite. J. Radioanal. Nucl. Chem. 2013, 295, 1153-1159. [CrossRef]

38. Deng, L.; Su, Y.; Su, H.; Wang, X.; Zhu, X. Sorption and desorption of lead (II) from wastewater by green algae Cladophora fascicularis. J. Hazard. Mater. 2007, 143, 220-225. [CrossRef] [PubMed]

39. Ma, F.; Qu, R.; Sun, C.; Wang, C.; Ji, C.; Zhang, Y.; Yin, P. Adsorption behaviors of Hg (II) on chitosan functionalized by amino-terminated hyperbranched polyamidoamine polymers. J. Hazard. Mater. 2009, 172, 792-801. [CrossRef] [PubMed]

40. Zhu, Q.; Li, Z. Hydrogel-supported nanosized hydrous manganese dioxide: Synthesis, characterization, and adsorption behavior study for $\mathrm{Pb}^{2+}, \mathrm{Cu}^{2+}, \mathrm{Cd}^{2+}$ and $\mathrm{Ni}^{2+}$ removal from water. Chem. Eng. J. 2015, 281, 69-80. [CrossRef]

41. Mukhopadhyay, A.; Pandey, P.; Chakraborty, T. Blue-and red-shifting CH..O hydrogen bonded complexes between haloforms and ethers: Correlation of donor $\mathrm{\vee C}-\mathrm{H}$ spectral shifts with $\mathrm{C}-\mathrm{O}-\mathrm{C}$ angular strain of the acceptors. J. Phys. Chem. A 2010, 114, 5026-5033. [CrossRef] [PubMed]

42. Cheung, W.H.; Szeto, Y.S.; McKay, G. Intraparticle diffusion processes during acid dye adsorption onto chitosan. Bioresource Technol. 2007, 98, 2897-2904. [CrossRef]

43. Wang, P.; Yin, L.; Wang, J.; Xu, C.; Liang, Y.; Yao, W.; Wang, X.; Yu, S.; Chen, C.; Sun, Y.; et al. Superior immobilization of U (VI) and ${ }^{243} \mathrm{Am}$ (III) on polyethyleneimine modified lamellar carbon nitride composite from water environment. Chem. Eng. J. 2017, 326, 863-874. [CrossRef]

44. Futalan, C.M.; Kan, C.C.; Dalida, M.L.; Hsien, K.J.; Pascua, C.; Wan, M.W. Comparative and competitive adsorption of copper, lead, and nickel using chitosan immobilized on bentonite. Carbohyd. Polym. 2011, 83, 528-536. [CrossRef]

45. Park, J.H.; Ok, Y.S.; Kim, S.H.; Cho, J.S.; Heo, J.S.; Delaune, R.D.; Seo, D.C. Competitive adsorption of heavy metals onto sesame straw biochar in aqueous solutions. Chemosphere 2016, 142, 77-83. [CrossRef] [PubMed]

46. Feng, Y.; Gong, J.L.; Zeng, G.M.; Niu, Q.Y.; Zhang, H.Y.; Niu, C.G.; Deng, J.H.; Yan, M. Adsorption of Cd(II) and $\mathrm{Zn}(\mathrm{II})$ from aqueous solutions using magnetic hydroxyapatite nanoparticles as adsorbents. Chem. Eng. J. 2010, 162, 487-494. [CrossRef]

47. Jiang, M.; Jin, X.; Lu, X.Q.; Chen, Z. Adsorption of Pb(II), Cd(II), Ni(II) and Cu(II) onto natural kaolinite clay. Desalination 2010, 252, 33-39. [CrossRef]

48. Bachmaf, S.; Planer-Friedrich, B.; Merkel, B.J. Effect of sulfate, carbonate, and phosphate on the uranium (VI) sorption behavior onto bentonite. Radiochim. Acta 2008, 96, 359-366. [CrossRef]

49. Lee, S.Y.; Cha, W.S.; Kim, J.G.; Baik, M.H.; Jung, E.C.; Jeong, J.T.; Kim, K.; Chung, S.Y.; Lee, Y.J. Uranium (IV) remobilization under sulfate reducing conditions. Chem. Geol. 2014, 370, 40-48. [CrossRef] 
50. Sanding, A.; Bruno, J. The solubility of $\left(\mathrm{UO}_{2}\right)_{3}\left(\mathrm{PO}_{4}\right)_{2} \bullet 4 \mathrm{H}_{2} \mathrm{O}$ (s) and the formation of U(VI) phosphate complexes: Their influence in uranium speciation in natural waters. Geochim. Cosmochim. Acta 1992, 56, 4135-4145. [CrossRef]

51. Mehta, V.S.; Maillot, F.; Wang, Z.; Catalano, J.G.; Giammar, D.E. Effect of co-solutes on the products and solubility of uranium (VI) precipitated with phosphate. Chem. Geol. 2014, 364, 66-75. [CrossRef]

52. Perassi, I.; Borgnino, L. Adsorption and surface precipitation of phosphate onto $\mathrm{CaCO}_{3}-$ montmorillonite: Effect of pH, ionic strength and competition with humic acid. Geoderma 2014, 232, 600-608. [CrossRef] 


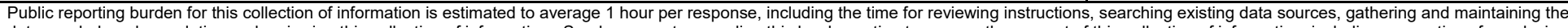

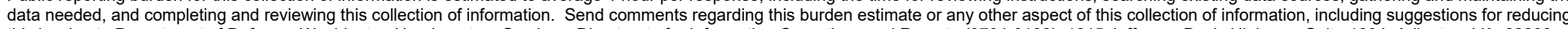

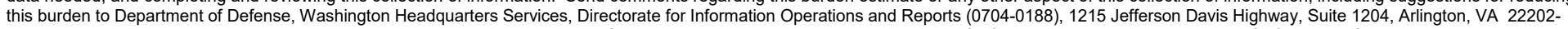

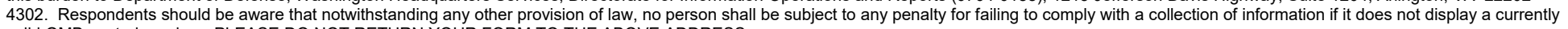
valid OMB control number. PLEASE DO NOT RETURN YOUR FORM TO THE ABOVE ADDRESS.
1. REPORT DATE (DD-MM-YYYY)
2. REPORT TYPE
3. DATES COVERED (From - To)

July 2020

\section{TITLE AND SUBTITLE}

Final

5a. CONTRACT NUMBER

Kinetics and Thermodynamics of Uranium (VI) Adsorption onto Humic Acid Derived from Leonardite

\section{5b. GRANT NUMBER}

5c. PROGRAM ELEMENT NUMBER

$63372803 \mathrm{~F}$

6. AUTHOR(S)

Fande Meng, Guodong Yuan, Steven L. Larson, John H. Ballard,

Jeremy R. White, Zikri Arslan, and Fengxiang X. Han

5d. PROJECT NUMBER

458170

5e. TASK NUMBER

5

5f. WORK UNIT NUMBER

\section{PERFORMING ORGANIZATION NAME(S) AND ADDRESS(ES)}

U.S. Army Engineer Research and Development Center

Environmental Laboratory

3909 Halls Ferry Road

8. PERFORMING ORGANIZATION REPORT

Vicksburg, MS 39180 NUMBER

ERDC/EL MP-20-9

9. SPONSORING / MONITORING AGENCY NAME(S) AND ADDRESS(ES)

Budget and Programs Div

Department of the Army USACE

441 G Street NW

Washington, DC 20314

10. SPONSOR/MONITOR'S ACRONYM(S)

USACE

11. SPONSOR/MONITOR'S REPORT NUMBER(S)

\section{DISTRIBUTION / AVAILABILITY STATEMENT}

Approved for public release; distribution is unlimited.

\section{SUPPLEMENTARY NOTES}

Originally published in International Journal of Environmental Research and Public Health, May 2, 2019.

Collaborative work was conducted by the U.S. Army ERDC and Jackson State University via Cooperative Agreement W912HZ-16-2-002.

\section{ABSTRACT}

Humic acid (HA) is well known as an inexpensive and effective adsorbent for heavy metal ions. However, the thermodynamics of uranium (U) adsorption onto HA is not fully understood. This study aimed to understand the kinetics and isotherms of U(VI) adsorption onto HA under different temperatures from acidic water. A leonardite-derived HA was characterized for its ash content, elemental compositions, and acidic functional groups, and used for the removal of U (VI) from acidic aqueous solutions via batch experiments at initial concentrations of $0-100 \mathrm{mgL}^{-1}$ at 298,308 and $318 \mathrm{~K}$. ICP-MS was used to determine the U(VI) concentrations in solutions before and after reacting with the HA. The rate and capacity of HA adsorbing U(VI) increased with the temperature. Adsorption kinetic data was best fitted to the pseudo second-order model. This, together with FTIR spectra, indicated a chemisorption of U(VI) by HA. Equilibrium adsorption data was best fitted to the Langmuir and Temkin models. Thermodynamic parameters such as equilibrium constant $\left(\mathrm{K}_{0}\right)$, standard Gibbs free energy $\left(\Delta \mathrm{G}^{0}\right)$, standard enthalpy change $\left(\Delta \mathrm{H}^{0}\right)$, and standard entropy change $\left(\Delta \mathrm{S}^{0}\right)$, indicated that $\mathrm{U}(\mathrm{VI})$ adsorption onto $\mathrm{HA}$ was endothermic and spontaneous. The co-existence of cations $\left(\mathrm{Cu}^{2+}, \mathrm{Co}^{2+}, \mathrm{Cd}^{2+}\right.$ and $\left.\mathrm{Pb}^{2+}\right)$ and anions $\left(\mathrm{HPO}_{4}{ }^{2-}\right.$ and $\left.\mathrm{SO}_{4}{ }^{2-}\right)$ reduced $\mathrm{U}(\mathrm{VI})$ adsorption. The high propensity and capacity of leonardite-derived HA adsorbing U(VI) suggests that it has the potential for cost-effective removal of U(VI) from acidic contaminated waters.

\section{SUBJECT TERMS}

Humic acid; uranium (VI); FTIR; adsorption; chemisorption

\begin{tabular}{|c|c|c|c|c|c|}
\hline \multicolumn{3}{|c|}{ 16. SECURITY CLASSIFICATION OF: } & \multirow{2}{*}{$\begin{array}{l}\begin{array}{l}\text { 17. LIMITATION } \\
\text { OF ABSTRACT }\end{array} \\
\text { SAR }\end{array}$} & \multirow{2}{*}{$\begin{array}{l}\begin{array}{l}\text { 18. NUMBER } \\
\text { OF PAGES }\end{array} \\
16\end{array}$} & \multirow{2}{*}{$\begin{array}{l}\text { 19a. NAME OF RESPONSIBLE PERSON } \\
\begin{array}{l}\text { 19b. TELEPHONE NUMBER } \\
\text { (include area code) }\end{array}\end{array}$} \\
\hline $\begin{array}{l}\text { a. REPORT } \\
\text { Unclassified }\end{array}$ & $\begin{array}{l}\text { b. ABSTRACT } \\
\text { Unclassified }\end{array}$ & $\begin{array}{l}\text { c. THIS PAGE } \\
\text { Unclassified }\end{array}$ & & & \\
\hline
\end{tabular}

